\title{
Encoding Processes and Sex-Role Preferences
}

\author{
Robert V. Kail, Jr. and Laura E. Levine \\ University of Michigan
}

\begin{abstract}
Seven- and 10-year-old children were tested on memory and sex-role preference tasks. The memory task was the Wickens release from proactive inhibition paradigm in which short-term recall of words is tested on successive trials. On Trials 1-4, words were selected from one of two categories, either words with masculine or feminine connotations. On Trial 5 , words were drawn from the second category. Sex-role preference was assessed by asking the child to select his favorite pictures from an array that included masculine and feminine items. Recall by boys at both ages increased following a shift between words with masculine or feminine connotations, suggesting that this dimension of a word's meaning was encoded in memory. Recall by girls who selected a feminine item as their favorite on the sex-role preference task increased following a category shift: recall by girls who chose a masculine item did not increase. These results are discussed in relation to previous research on the attributes of encoding in children's memory.
\end{abstract}

There is considerable evidence to indicate that words are encoded in memory both as unique items and as members of conceptual classes. Many classes or attributes of encoding have been identified using the "release from proactive inhibition (PI)" task (Wickens, 1972). In this task, a trial consists of the presentation of two words to be remembered, a distracting task for a brief period, and an interval for recall. On the first trial, recall is nearly perfect; on immediately succeeding trials it declines when the words presented share a common attribute. If words presented on a later trial are members of a different conceptual class, recall may improve, indicating that the new words are encoded differently in memory (Wickens, 1972). For example, Kail and Schroll (1974) found that recall by 8 - and 11-year-old children declined on Trials 1 to 3 when all the words referred to animals, but increased on Trial 4 when the words

Support for this study was received by the first author from a Predoctoral Fellowship from the Horace H. Rackham School of Graduate Studies, University of Michigan, and by the second author from a traineeship under an NICHD training grant (HD 00149). The authors are indebted to Victoria Pickering for her assistance in testing children, and to several colleagues, John Hagen, Bob Jongeward, Lorraine Nadelman, and Harold Stevenson, for their comments on this manuscript. The cooperation of the pupils and staff of the Spencer Road Elementary School, Brighton, Michigan, is gratefully acknowledged. Portions of these data were presented at the 1975 meetings of the Society for Research in Child Development and the Midwestern Psychological Association, in Denver and Chicago, respectively. Author Kail's address: Department of Psychology, University of Pittsburgh, Pittsburgh, Pennsylvania, 15260. 
referred to parts of the body. Thus there was evidence suggesting that one attribute of encoding for children of both ages was the taxonomic class of the word.

An attribute of encoding that has been investigated with adults but not with children is the masculine-feminine connotation of a word. Ickes (cited in Wickens, 1972) found a small but significant increase in recall following category shifts between words with masculine (e.g., butler, tuxedo, rooster) and feminine (e.g., queen, nylons, cow) connotations. While the masculine-feminine connotation of a word apparently was not a salient attribute of encoding for these adult subjects, it might be more important at other developmental levels. Indeed, research on the development of sex-role knowledge and preferences (Nadelman, 1974) suggests that the masculine-feminine connotation of an object may be a particularly salient attribute in the encoding processes of young children. Furthermore, the degree to which the child is influenced by sex-role preferences might be related to his (her) encoding processes. That is, the child who shows a marked sex-role preference may encode along the masculine-feminine dimension to a greater extent than the child who is less extreme in his (her) sex-role preferences.

In the present experiment the role of the masculine-feminine connotation of a word as an attribute of encoding in children's memory was investigated. The stimuli were words describing games or activities appropriate either for boys or for girls. Seven- and 10-year-old boys and girls were assigned to control or experimental conditions for the release from PI task. In the control condition, subjects were tested with either masculine or feminine pairs of words on all five trials. In the experimental condition, subjects were tested with words from one category on Trials 1 to 4 and with words from the other category on Trial 5. Subjects in the experimental condition were tested subsequently on a sex-role preference task (from Nadelman, 1974) to determine if an improvement in recall following a category shift was related to the child's sex-role preference.

\section{METHOD}

\section{Subjects}

The subjects were 240 children from grades $1-2$ and grades $4-5$ in a predominantly white school in a small Michigan town. Thirty boys and 30 girls at each age were assigned to the control condition and an equal number was assigned to the experimental condition, resulting in eight groups of 30 subjects [age $(2) \times \operatorname{sex}(2) \times$ condition(2)]. The median age of the younger subjects was 7;7 years and of the older subjects, 10;9 years (ranges: $6 ; 0-8 ; 4,9 ; 0-12 ; 1$ ). 
Release from PI Task

Stimuli. Ten pairs of words were used (see Table 1), five pairs of words with masculine connotations and five pairs of words with feminine connotations. Words were selected from a larger sample on the basis of data obtained in pretesting. In the pretest, 14 7-year-old boys and girls were asked to judge whether a boy or girl would play or do various games and activities. Words selected were those both boys and girls unanimously or near-unanimously agreed were appropriate for a child of one sex only. An effort was made to equate words in the two categories on the basis of length and acoustic properties, while minimizing associations within each pair.

Procedure. The instructions and stimulus materials were prerecorded and presented through headphones. On each trial, in the first $5 \mathrm{sec}$ a child was told to remember two words and repeated them aloud. A distraction task designed to prevent rehearsal of the words followed in which the child named colors at the rate of one color per second for $15 \mathrm{sec}$ from an array presented by the experimenter. Then there was a $10 \mathrm{sec}$ interval for the child to recall aloud the two words presented on that trial. The next trial started immediately after the recall interval.

The child was given one practice trial with words unrelated to the test words. Then there were five experimental trials. For 14-16 subjects in each control group the words on the five trials were masculine and for the remaining subjects the words were feminine. For subjects in the experimental groups the words were selected from one category (e.g., masculine) on Trials 1 to 4 , but from the other category (e.g., feminine) on Trial 5. As many shifts were made from masculine to feminine pairs as from feminine to masculine pairs. The presentation of pairs of words across trials was counterbalanced; each pair was presented on each trial with equal frequency.

\section{Sex-Role Preference Task}

There were 40 pictures of various objects and activities drawn on $3 \frac{1}{2} \times 5$ in. cards; 20 were masculine-stereotyped and 20 were feminine-

TABLE 1

Word Pairs Used in thF. EXPeriment

Masculine pairs

hunting/airplane

wrestling/soldier

fishing/car

pistol/football

darts/cowboy
Feminine pairs

cooking/hopscotch earrings/jumprope sewing/house dance/bracelet purse/doll 
stereotyped pictures. The experimenter arranged eight cards in two rows in front of the child. Each row contained two masculine and two feminine items. The child selected the card he (she) liked the best, and the experimenter removed that card from the display. In like manner, the child chose second, third, and fourth favorite cards. Then all remaining cards were picked up and a new set of eight items was presented. There were five trials, using different stimuli on each trial. Finally, the child was shown the five items selected first on each trial, and he (she) chose the single item liked best.

\section{General Procedures}

The testing session for each task lasted approximately $5 \mathrm{~min}$. From 2-7 weeks after the administration of the memory task, 118 of the 120 subjects in the experimental condition were given the sex-role preference task. All testing was conducted in isolated rooms within the school by one of three white experimenters during the months February-April 1974. An equal number of boys and girls in each condition was tested by male and female experimenters.

\section{RESULTS}

Three aspects of the data are of particular interest: performance on the release from PI task, performance on the sex-role preference task, and the relationship between performance on these two tasks. Because preliminary analyses revealed that children tested by the different experimenters did not differ in overall recall, improvement on the shift trial, nor in sex-role preference, data from all experimenters were combined.

\section{Release from PI Task}

Scores for each trial ranged from $0-2$. One point was given for each word recalled correctly, regardless of the order of recall. Recall data as a function of trials for boys and girls in the control and experimental groups are presented in Fig. 1 for the 7-year-olds and in Fig. 2 for the 11-year-olds.

Analysis of the data from Trials 1-4 indicated that older children recalled more words than did younger children, $F(1,208)=17.98$, $p<.001$, and that performance declined over trials, $F(3,624)=14.56$, $p<.001$. Recall by children in the experimental and control groups did not differ, and insignificant $F$ s were obtained for the condition $\times$ trials interaction and all higher order interactions involving the condition and trials variables. These results indicate that performance of the groups was essentially alike prior to the shift trial.

A second analysis was performed on the data from Trials 4 and 5 to examine the effects of the category shift on recall. Again, there were significant main effects due to trials, $F(1,232)=18.42, p<.001$, and age, 


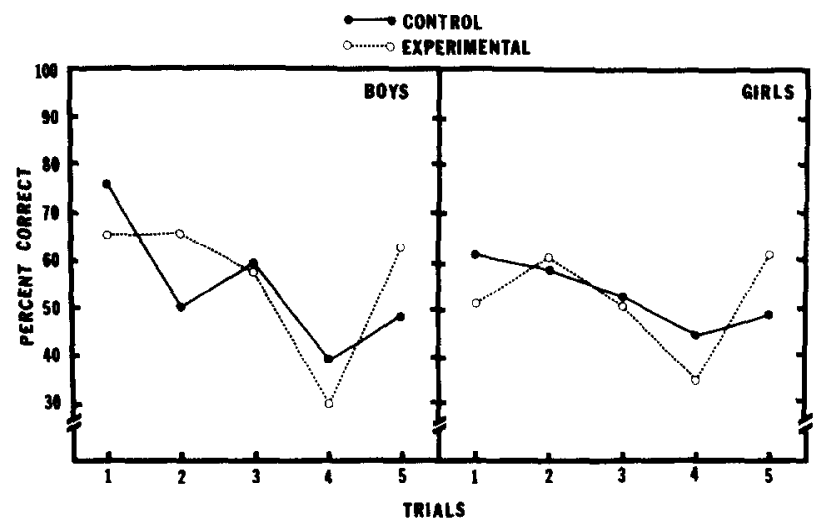

FIG. 1. Percentage correct as a function of trials for 7-year-old boys and girls in the control and experimental groups.

$F(1,232)=18.75, p<.001$. More important for the purposes of the experiment, there was a condition $\times$ trials interaction, $F(1,232)=7.40$, $p<.01$. The experimental and control groups did not differ on Trial 4 , but recall by the experimental group was superior on Trial $5, F(1,232)$ $=16.96, p<.001$. In the experimental group, there was a greater increase in recall when the masculine or feminine connotation of the words on Trial 5 matched the sex of the child than when the words connoted the opposite sex, but this effect was not significant.

\section{Sex-Role Preference Task}

The number of subjects choosing a masculine or feminine object as the most favorite item is presented in Table 2 with the mean number of masculine choices in the child's five and 20 most preferred items. Both younger and older boys typically chose a masculine object as their

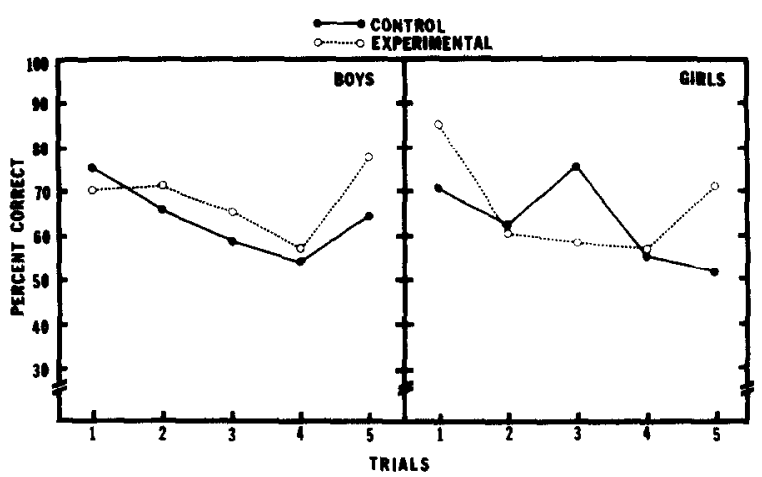

FIG. 2. Percentage correct as a function of trials for 11-year-old boys and girls in the control and experimental groups. 


\section{TABLE 2}

Selection of Masculine and feminine Items on the Sex-Role Preference Task

\begin{tabular}{llccc}
\hline & & \multicolumn{2}{c}{$\begin{array}{c}\text { Mean number of } \\
\text { masculine items } \\
\text { selected in }\end{array}$} \\
\cline { 3 - 4 } & $\begin{array}{c}\text { Favorite } \\
\text { item }\end{array}$ & $N$ & $\begin{array}{c}\text { Five most } \\
\text { preferred }\end{array}$ & $\begin{array}{c}\text { 20 Most } \\
\text { preferred }\end{array}$ \\
\hline Boys & & & & \\
7 7-year-olds & masculine & 30 & 4.95 & 18.60 \\
10-year-olds & feminine & 0 & - & - \\
masculine & 29 & 5.00 & 18.60 \\
G-year-olds & feminine & 1 & 4.00 & 19.00 \\
10-year-olds & masculine & 10 & 2.60 & 7.60 \\
& feminine & 19 & 0.25 & 3.00 \\
& masculine & 16 & 2.85 & 9.60 \\
& feminine & 13 & 0.70 & 5.60 \\
\hline
\end{tabular}

favorite, $\chi^{2} \mathrm{~s}(1) \geq 27.2, p<.001$. There was some tendency for younger girls to choose a feminine object, $\chi^{2}(1)=2.80, p<.10$, but older girls selected masculine and feminine items with approximately equal frequency, $\chi^{2}(1)<1$.

\section{Relationship between Performance on Memory and Preference Tasks}

To examine the relationship between sex-role preference and performance on the PI task, recall by girls selecting a masculine or feminine item as their favorite was compared. ${ }^{1}$ These data are presented in Fig. 3 with data from appropriate control groups. For 7-year-old girls who selected a masculine item, recall did not change between Trials 4 and $5, t(9)=1.08$, but increased for younger girls who selected a feminine item, $t(18)=3.62, p<.01$. At the 10 -year-old level, recall was stable between Trials 4 and 5 for girls who selected a masculine item, $t<1$, but increased for girls who selected a feminine item, $t(12)=2.92$, $p<.02$. Thus girls with more sex-typed choices on the sex-role preference task were the only girls who showed evidence of encoding the masculine-feminine dimension in the release from PI task.

\section{DISCUSSION}

That children as young as age 7 years may encode the masculinefeminine connotation of a word is consistent with previous findings of

\footnotetext{
' Because only one boy selected a feminine item as his favorite on the sex-role preference task, these comparisons are restricted to the data from the girls.
} 


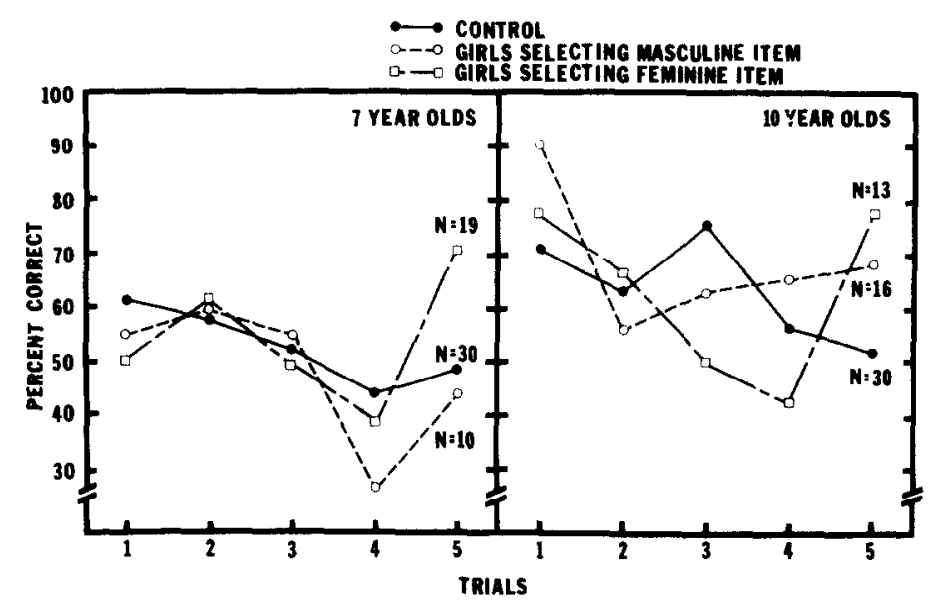

FIG. 3. Percentage correct as a function of trials for 7- and 11-year-old girls in the experimental condition who selected masculine or feminine items as their favorites on the sex-role preference task, and girls in the control condition.

semantic encoding in young children (e.g., Hagen, Jongeward, \& Kail, 1975). Further, when recall increased following a shift between masculine and feminine items, performance returned to the level of performance on Trial 1-a stronger effect than has been found with adults. Thus an attribute of a word's meaning may be especially salient in the encoding processes of children, but less so with adults.

Encoding processes measured with the release from PI task seem to be related to the child's choice of items on the sex-role preference task. There was a striking correspondence between the strong increases in recall following a shift between words with masculine and feminine connotations and the extreme preference for sex-appropriate items by boys at both ages. The picture was more complicated for girls, but again the memory and preference data were consistent. Individual differences in sex-typing of girls were detected in both tasks. Girls who selected more feminine items on the sex-role preference task also showed evidence of encoding the masculine-feminine connotation of a word; girls who did not prefer feminine items over masculine ones on the sexrole preference task did not appear to encode the words along a masculinefeminine dimension.

The results of the present study also complement previous investigations of the influences of sex-role development on cognitive and intellectual processes. Boys and girls apparently do not differ in basic cognitive skills, such as perception, learning, and memory (Maccoby \& Jacklin, 1974), but superior intellectual ability in children has frequently been associated with cross-sex typing (Maccoby, 1966). Boys in the present study were highly consistent in their selection of masculine items on the 
sex-role preference task. Yet boys' performance on the PI task resembled that of girls who were similarly extreme in their selection of feminine items, rather than performance of girls who selected masculine items. Apparently both the direction and degree of stereotyping must be considered to understand the relations between sex-role socialization and cognitive processing.

Thus the encoding of a word following a single auditory presentation of approximately $1-\mathrm{sec}$ may be influenced by some of the same factors that affect the child's longer-term social preferences. Future investigations of similar consistencies in performance across tasks should help to clarify the ways in which children process information.

\section{REFERENCES}

Hagen, J. W., Jongeward, R. H., \& Kail, R. V. Cognitive perspectives on the development of memory. In H. W. Reese (Ed.), Advances in child development and behavior (Vol. 10). New York: Academic Press, 1975.

Kail, R. V., \& Schroll, J. T. Evaluative and taxonomic encoding in children's memory. Journal of Experimental Child Psychology, 1974, 18, 426-437.

Maccoby, E. E. Sex differences in intellectual functioning. In E. E. Maccoby (Ed.), The development of sex differences. Stanford, California: Stanford University Press, 1966.

Maccoby, E. E., \& Jacklin, C. N. The psychology of sex differences. Stanford, California: Stanford University Press, 1974.

Nadelman, L. Sex identity in American children: Memory, knowledge, and preference tests. Development Psychology, 1974, 10, 413-417.

Wickens, D. D. Characteristics of word encoding. In A. W. Melton \& E. Martin (Eds.), Coding processes in human memory. Washington. D.C.: Winston \& Sons, 1972.

RECEIVED: December 13, 1974; REVISED: July 2, 1975. 